celiac disease in children? $f$ Pediatr Gastroenterol Nutr 1983; 2: 428-33.

28 Greco L, Mayer M, Grimaldi M, Follo D, De Ritis G, Auricchio $S$. The effect of early feeding on the onset of symptoms in celiac disease. $\mathcal{F}$ Pediatr Gastroenterol Nutr 1985; 4: 52-5

29 Greco L, Auricchio S, Mayer M, Grimaldi M. Case control study on nutritional risk factors in celiac disease. $\mathcal{F}$ Pediatr Gastroenterol Nutr 1988; 7: 395-9.

30 Shewry P, Tatham A, Kasarda D. Cereal proteins and coeliac disease. In: Marsh $M$, ed. Coeliac disease.
Oxford: Blackwell Scientific Publications, 1992: 30148

31 Collin P, Hällström O, Mäki M, Viander M, Keyriläinen O. Atypical coeliac disease found with serologic screening. Scand $\mathcal{F}$ Gastroenterol 1990; 25: 245-50.

32 Holmes GK, Prior P, Lane MR, Pope D, Allan RN. Malignancy in coeliac disease - effect of a gluten free diet. Gut 1989; 30: 333-8.

33 Grodzinsky E, Franzen L, Hed J, Ström M. High prevalence of celiac disease in healthy adults revealed by antigliadin antibodies. Ann Allergy 1992; 69: 66-70.

\title{
Experimental glomerulonephritis - a decorous approach to
} treatment

The most important factor leading to progressive renal damage in glomerulonephritis is the accumulation of extracellular matrix which can be measured in histological sections by fluorescent antibody staining for fibronectin. The excess matrix accumulates because of overactivity of transforming growth factor-beta (TGF- $\beta$ ) which, after tissue injury, is released initially from degranulating platelets and this then leads to autoinduction of $\mathrm{TGF}_{-\beta}$ production by local tissue cells. It seems possible, therefore, that progressive damage might be prevented by the inhibition of TGF- $\beta$.

There are three isoforms of $\mathrm{TGF}_{-\beta}: \mathrm{TGF}_{-\beta 1}, \mathrm{TGF}_{-\beta 2}$, and $\mathrm{TGF}_{-\beta 3}$. An anti-TGF- ${ }_{-\beta 1}$ antibody given to glomerulonephritic rats has been shown to inhibit matrix production in the glomeruli. One of the effects of $\mathrm{TGF}_{-\beta}$ is to induce the production in the tissues of a proteoglycan molecule called decorin. This in turn neutralises $\mathrm{TGF}_{-\beta}$ and, unlike the isoform specific antibody, it affects all three isoforms.

Workers in Utah and California (Wayne A Border and colleagues, Nature 1992; 360: 361-4) have given intravenous decorin to rats with antithymocyte serum induced glomerulonephritis. After the injection of antithymocyte serum the rats were given either no decorin or daily intravenous injections of either bovinte or recombinant human decorin for two, four, or six days. The animals were killed after seven days and the amount of fibronectin deposited in their glomeruli was quantified. Those given no decorin or treated for only two days had uniformly high concentrations of fibronectin deposition but the rats treated for four or six days had much lower concentrations, which approached those found in normal controls. When glomerular deposition of other matrix components thought to be specifically induced by $\mathrm{TGF}_{-\beta}$ was measured the results were very similar. Urinary protein excretion on day 7 after the antithymocyte serum was also reduced if the rats had been given decorin for four or six days. Urine protein to creatinine ratios were 0.7 in normal rats, 15.2 in glomerulonephritic rats given no decorin, 14.8 in those given decorin for two days, and 2.4 in those given it for four or six days $(p=0.01$ for four or six days decorin compared with no decorin).

Radiolabelled decorin given intravenously accumulates in the kidneys, liver and lungs and the authors suggest, therefore, that it may prove useful in the treatment of proliferative diseases in these three organs. The different isoforms of $\mathrm{TGF}_{-\beta}$ may be implicated in different diseases, for instance $\mathrm{TGF}_{-\beta 1}$ is raised in glomerulonephritis and $\mathrm{TGF}_{-\beta 2}$ in the eye in proliferative vitreoretinopathy and in the skin in systemic sclerosis. The availability of human recombinant decorin should make problems with immunogenicity less likely.

Clearly, from rat to human disease is a large step and the possibility of undesired effects especially in growing and developing organs must be explored but perhaps we can hope that work along these lines may point towards treatment of hitherto untreatable diseases. 